\title{
Flexible High Aspect Ratio Wing: Low Cost Experimental Model and Computational Framework
}

\author{
Alessandro Pontillo * David Hayes $†$ Gaetan Dussart $\ddagger$ Guillermo Lopez $§$ \\ Martin Carrizalez , Sezsy Yusuf ", and Mudassir Lone ${ }^{* *}$ \\ Cranfield University, Cranfield, Bedfordshire, United Kingdom, MK43 OAL
}

\begin{abstract}
Aircraft concepts of tomorrow, such as high aspect ratio wing aircraft, are far more integrated between technical disciplines and thus require multi-disciplinary design approaches. Design tools able to predict associated dynamics need to be developed if such wing concepts are to be matured for use on future transport aircraft. The Cranfield University Beam Reduction and Dynamic Scaling (BEARDS) Programme provides a framework that scales a conceptual full size aircraft to a cantilevered wing model of wind tunnel dimensions, such that there is similitude between the static and dynamic behaviour of the model and the full size aircraft. This process of aeroelastically scaled testing combines the technical disciplines of aerodynamics, flight mechanics and structural dynamics, to provide a means by which future concept aircraft can be de-risked and explored. Data acquisition from wind tunnel testing can then be used to validate fluid-structure interaction frameworks that model the aeroelastic effect on the flight dynamics of the aircraft. This paper provides an overview of the BEARDS methodology, and focuses on the Phase I of the programme, being the development of a reduced Cranfield A-13 aircraft cantilevered wing, to mitigate risk associated with the manufacturing and instrumentation approach. It is shown that a low cost acquisition system of commercial Inertial Measurement Units (IMUs) can measure the response of the wing within the desired frequency range. Issues associated with the Phase $I$ testing are discussed, and methods are proposed for the Phase II programme that allow these problems to be resolved for a larger scale flexible wing with active control surfaces.
\end{abstract}

\section{Introduction}

The idea of similarity, ${ }^{1}$ both for static and dynamic behaviour, has been used extensively within the aerospace industry for validation of mathematical modelling tools and de-risking of novel concepts. Traditionally this idea, with the help of dimensional analysis, ${ }^{2}$ is most heavily applied within the aerodynamics domain to design experiments with geometrically scaled models such that the collected data is scalable. Wind tunnel tests are designed to ensure a degree of Reynolds number similarity and in other areas, test engineers strive to match other dimensionless parameters. Given the challenges faced by the aerospace sector today, the idea of similarity is being extended to more multi-disciplinary areas such as aeroelasticity ${ }^{3}$ and flight mechanics. ${ }^{4}$ In the past, as thoroughly discussed by Chambers, ${ }^{5}$ domains such as aerodynamics, flight mechanics and structural dynamics have each used dimensional analysis and scaled testing separately. Aircraft designs of the past ensured sufficient separation in these technical domains that allowed: (1) aerodynamicists to focus on geometric similarity, (2) flight dynamicists to focus on mass and inertial similitude and, (3) structural engineers to focus on the scaling of bending and torsional stiffnesses. However, the aircraft concepts of tomorrow ${ }^{6}$ are far more integrated and require close links between each of the technical

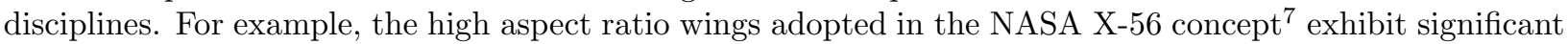

\footnotetext{
*PhD candidate, School of Aerospace, Transport and Manufacturing, a.pontillo@cranfield.ac.uk

${ }^{\dagger}$ PhD candidate, School of Aerospace, Transport and Manufacturing, d.hayes@cranfield.ac.uk

${ }^{\ddagger}$ PhD candidate, School of Aerospace, Transport and Manufacturing, g.x.dussart@cranfield.ac.uk

$\S$ Research Assistant, School of Aerospace, Transport and Manufacturing, g.lopez@cranfield.ac.uk

TPhD candidate, School of Aerospace, Transport and Manufacturing, martin.carrizales@cranfield.ac.uk

\|PhD candidate, School of Aerospace, Transport and Manufacturing, sezsy.yusuf@cranfield.ac.uk

** Lecturer, School of Aerospace, Transport and Manufacturing, m.m.lone@cranfield.ac.uk
} 


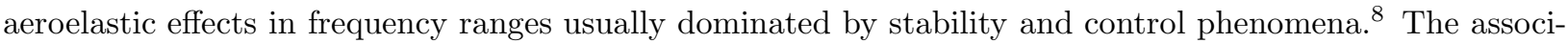
ated dynamics must be sufficiently understood and predictive design tools need to be developed if such wing concepts are to be matured for use on future transport aircraft. Aeroelastically scaled testing that combines the technical disciplines discussed earlier (defined by Collar ${ }^{9}$ ), is a means by which such a concept can be de-risked and explored.

The BEAm Reduction and Dynamic Scaling (BEARDS) programme aims to develop a process for the design, manufacture and testing of dynamically scaled High Aspect Ratio (HAR) wings for use in Cranfield's 8'x6' wind tunnel, complete with control surfaces and folding wingtips. The idea is to create a methodology that adopts scaling laws to allow experimental testing of wings that exhibit highly non-linear and flexible behaviour. Fully actuated Load Alleviation Functions (LAF) ${ }^{10}$ may be tested, lowering stuctural loads due to gusts by implementing both control surfaces ${ }^{11}$ and folding wingtip control. ${ }^{12}$ BEARDS is being run as a two phase programme:

(I) Phase I, which forms the body of this paper, aims to mitigate risks associated with theoretical modelling, modular design \& manufacture, instrumentation and the testing procedure, using a wind tunnel model designated eXperimental BEARD 1 (XB-1). These areas have been highlighted as the disciplines not widely published in literature, and thus have the most associated unknowns for the programme.

(II) Phase II, the eXperimental BEARD 2 (XB-2), takes an academic aircraft wing geometry through the whole BEARDS process of scaling, design, manufacture and testing.

\section{BEARDS Programme}

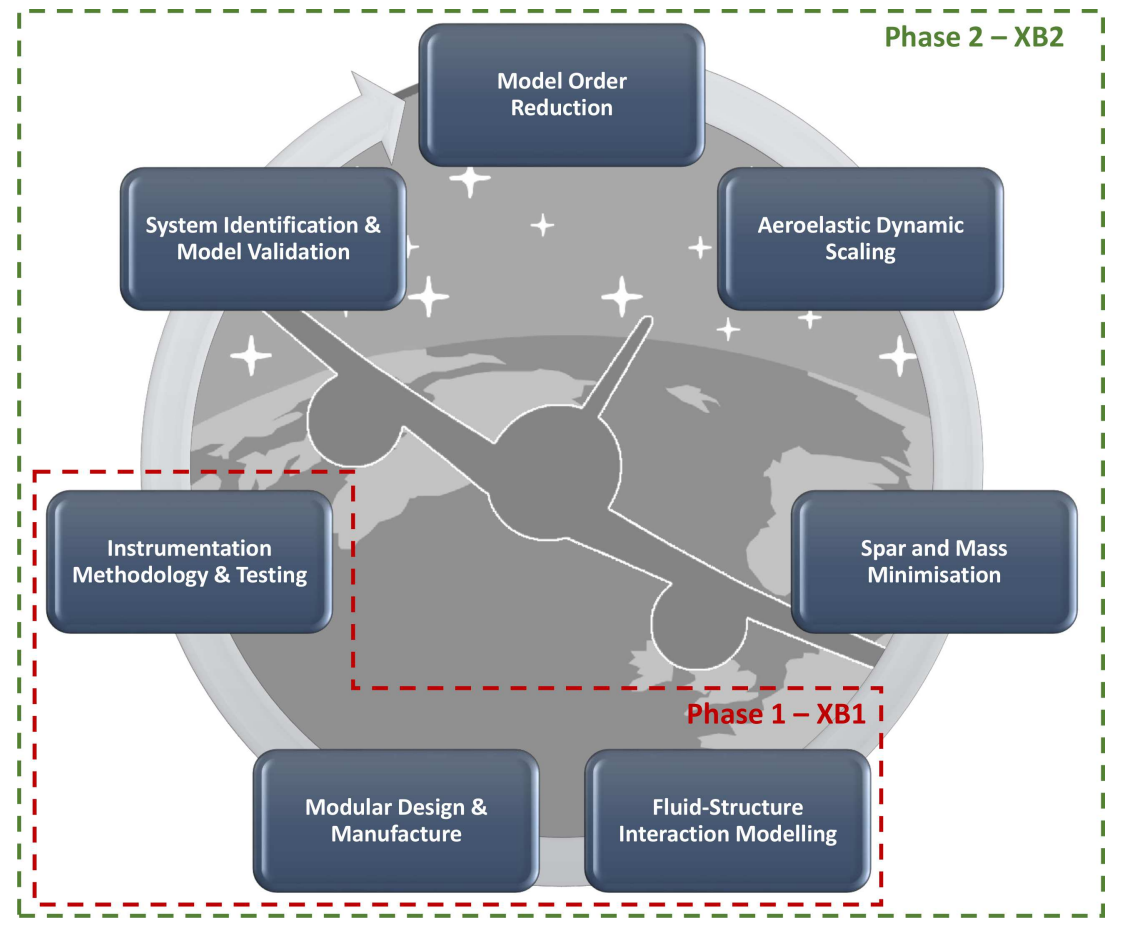

Figure 1. BEARDS Work Flow

Figure 1 shows the BEARDS workflow from the initial reduction of wing geometry to simple beam models through to the system identification \& model validation that completes the BEARDS process. Below each of the stages are discussed in further detail.

(i) Model Order Reduction:BEARDS considers the process of reducing a complex structural model to a one-dimensional beam element model maintaining the corresponding aerodynamic profile definitions at each of the nodes. Nacelles and fuselage definition are also required inline with ESDU $89014^{13}$ and $88031^{14}$ to account for the additional drag interference. Open source tools such as NeoCASS (Next 
generation Conceptual Aero Structural Sizing) $)^{15}$ can be used to generate such a model. An example of the Cranfield AX-1 aircraft ${ }^{16}$ as a BEARDS compatible model is given in Figure 2.

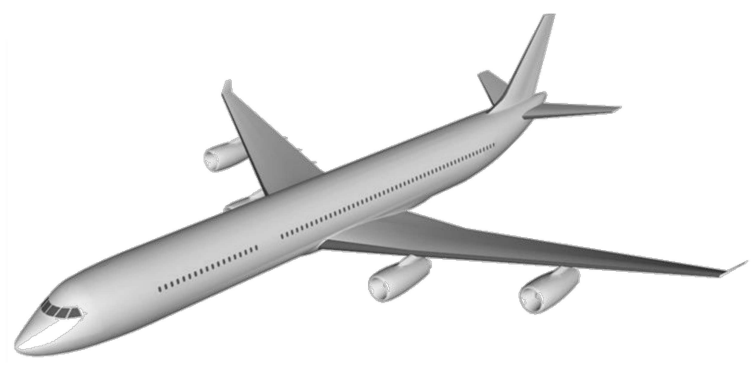

(a) AX-1 CAD Geometry

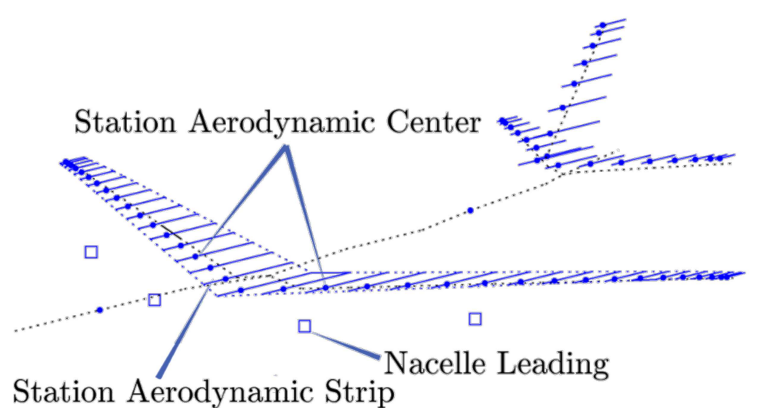

(c) AX-1 Aerodynamic Model

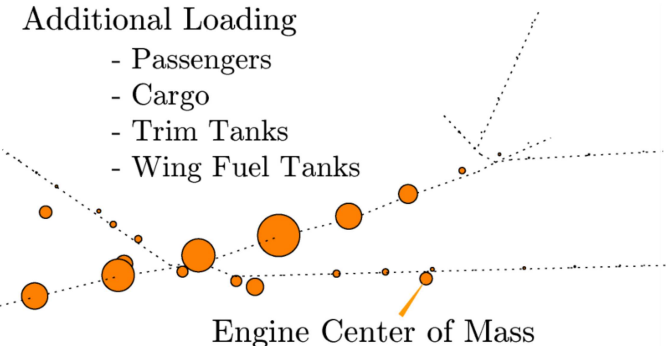

(b) AX-1 Lumped Mass Model

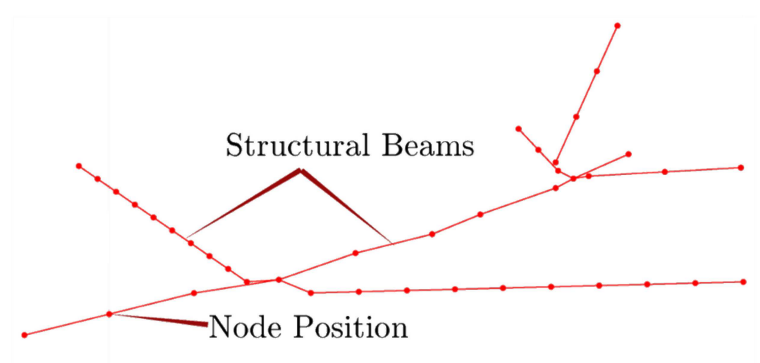

(d) AX-1 Structural Model

Figure 2. Cranfield AX-1 Aircraft Geometry in BEARDS compatible format

(ii) Aeroelastic Dynamic Scaling is needed to ensure motion similitude of the full-scale and sub-scaled model. ${ }^{5}$ The scaling law is derived based on geometrically nonlinear dynamic aeroelastic equations of motion, ${ }^{17}$ given in modal coordinates as:

$$
\underbrace{[M] \ddot{\boldsymbol{\eta}}+[C] \dot{\boldsymbol{\eta}}+[K] \boldsymbol{\eta}}_{\text {structure }}=\underbrace{\left[A_{k}\right] \boldsymbol{\eta}+\left[A_{c}\right] \dot{\boldsymbol{\eta}}+\left[A_{m}\right]}_{\text {aerodynamics }} \ddot{\boldsymbol{\eta}}+\underbrace{[M] \boldsymbol{a}_{\boldsymbol{g}}}_{\text {gravity }}
$$

As a result, several non-dimensional parameters are required to be consistent between the aircraft and model. The BEARDS method matches the Froude number, inertia and mass ratio, as well as the normalized eigenvectors.

(iii) Spar and Mass Minimisation is applied in order to reproduce the mass and stiffness distribution of a scaled model. Here the entire stiffness is modelled on the spar, considering the ideal skin to have zero stiffness. Given that in practice this is not achievable, the design parameter is for the skin to have a negligible impact of $5 \%$ on the overall stiffness. The skin does however have an important role in the mass distribution matching process as the weight of skin is estimated to be half the overall model weight. Thus, both the spar and the skin are considered when matching the mass matrix for the scaled model.

(iv) Fluid-Structure Interaction Modelling of the wing is predicted using the BEARDS Theoretical Model (BEARDS ${ }^{T M}$ ), which couples structural and aerodynamic codes to ascertain the aeroelastic response. The structural dynamics are modelled using Timoshenko ${ }^{18}$ beam bending theory, defined as:

$$
E I \frac{\partial^{4} w}{\partial y^{4}}+\rho A \frac{\partial^{2} w}{\partial t^{2}}-\rho I\left(1+\frac{E}{\kappa G}\right) \frac{\partial^{4} w}{\partial y^{2} \partial t^{2}}+\frac{\rho^{2} I}{\kappa G} \frac{\partial^{4} w}{\partial t^{4}}=q(y, t)+\frac{\rho I}{\kappa A G} \frac{\partial^{2} q(y, t)}{\partial t^{2}}-\frac{E I}{\kappa A G} \frac{\partial^{2} q}{\partial y^{2}}
$$

This is solved in a state space solver of mass and stiffness matrices, using a finite element approach, including a non-linear pre-stressed stiffness term as defined by Przemieniecki. ${ }^{19}$ The model is designed 
to solve for every nodal degree of freedom, but for computational efficiency an alternative Reduced Order Model (ROM) approach using modal states has also been made available.

The aerodynamic modelling uses a Modified Strip Theory (MST) method, which includes an unsteady aerodynamic model in state space form based on work by Theodorsen and Garrick ${ }^{20,21}$ and steady aerodynamic loads generated using MST for the wing as developed by Weissinger. ${ }^{22}$ Deyoung and Harper $^{23}$ expansion is used to account for span-wise three dimensional effects, accounting for the varying thickness, chord and twist. Figure 3 illustrates the BEARDS ${ }^{T M}$ architecture.
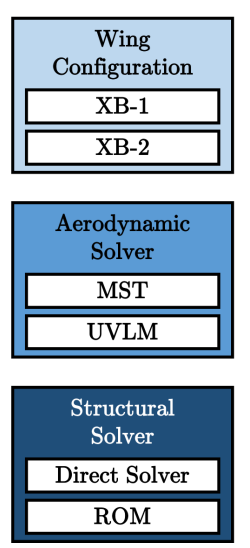
ROM

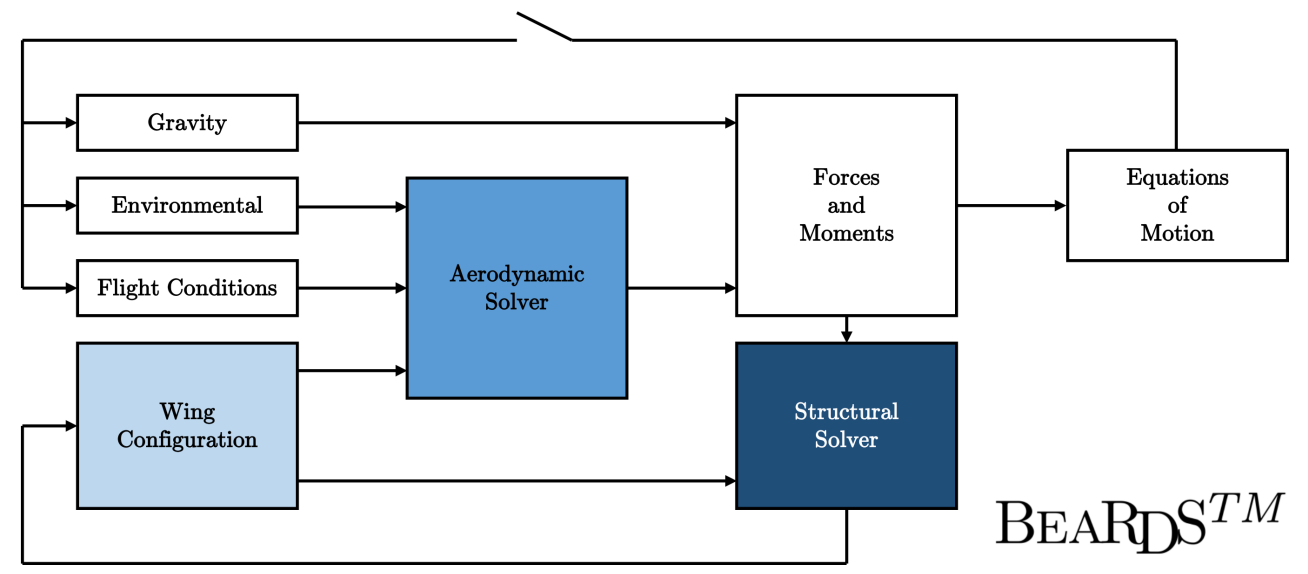

Figure 3. BEARDS Theoretical Model Architecture

(v) Modular Design \& Manufacture of the wing will allow different build definitions of the same wing, by dividing the model in three sections. For example, using a common interface a wing could have a configuration with a fixed wingtip (as per a conventional aircraft) or with an actively driven folding wingtip device. Modularity also helps keep costs low, as damage caused to part of the wing, means only a particular section needs to be replaced instead of the whole wing. The aim is to produce a low cost manufacturing methodology to allow experimentation of more wings at a low budget.

(vi) Instrumentation Methodology allows for the state of the wing to be measured during experimentation using a low cost aquisition system. The instrumentation allows the measurement of transverse and rotational displacements, velocities and accelerations. In Section III the low cost accelerometer and gyroscope system is discussed, but the BEARDS programme also allows for high speed camera image tracking and strain measurement based on Fibre Bragg Grating (FBG). ${ }^{24}$

Testing is conducted in the Cranfield University closed section 8'x6' and Weybridge open section wind tunnels. Steady state response is obtained by defining angle of attack and airspeed. A dynamic response can be measured from a control input into the aileron, spoiler or wing tip and alternatively through disturbing the flow, for example via a gust vane.

(vii) System Identification \& Model Validation is undertaken on the sub-scale model to validate $\mathrm{BEARDS}^{T M}$ framework where the wing modal properties and aerodynamic coefficients are to be identified. Modal properties will be first identified using ground vibration testing, while the aerodynamic coefficients will be identified in the wind tunnel environment with the input from the control surface.

\section{Phase I - eXperimental BEARD 1 (XB-1)}

The main goal of the eXperimental Beards 1 (XB-1) model is to develop a manufacturing and instrumentation methodology for a high flexiblity scaled wing model, to be used in the wind tunnel. XB-1 is preliminary to the dynamically scaled model XB-2 which will be tested in Cranfield University 8'x6' low speed wind tunnel. 


\section{A. eXperimental BEARD 1 Geometry, Design \& Manufacture}

The XB-1 geometry is taken from the previous Cranfield A-13 Voyager concept aircraft, see Figure 4 . For simplicity, the wing is designed without control surfaces and has a lower aspect ratio than XB-2, such that the deflections can be assumed to be linear, for assessing the linearised modelling approach.

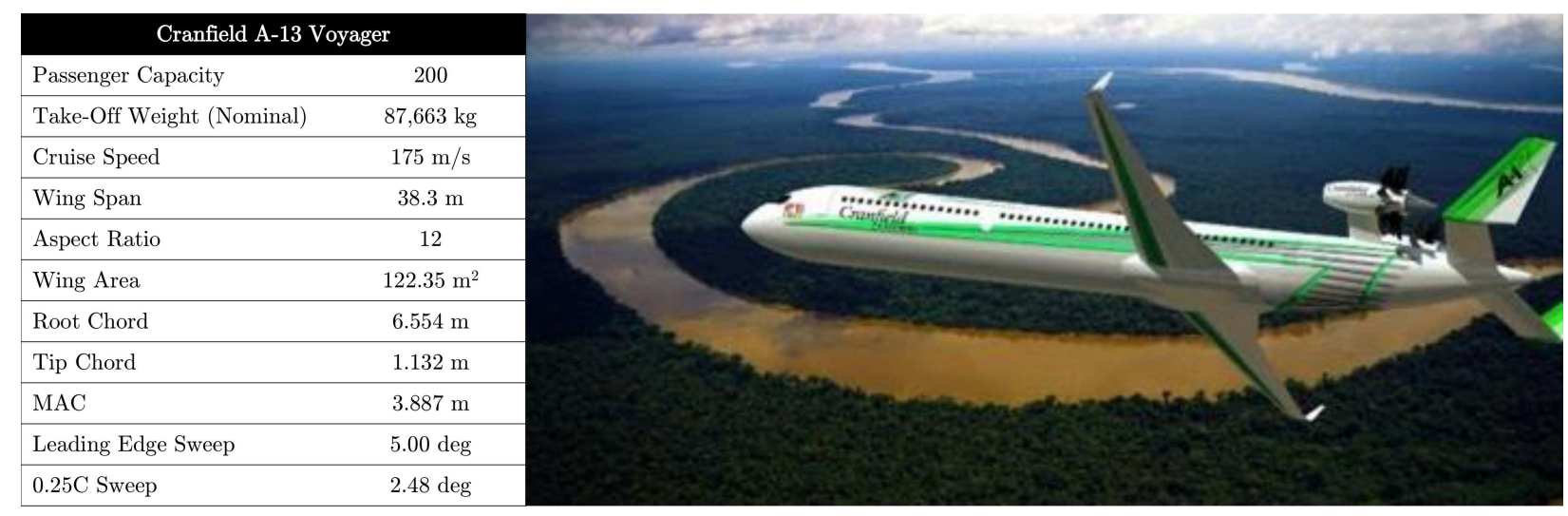

Figure 4. BEARDS XB-1 aerodynamic planform and spar geometry

From previous work in manufacturing the scaled A-13 wings, it was concluded that it is hard to model and predict the aeroelastic behaviour of such configurations, as all wings tested shared two problems: an increase of stiffness in tension, which is challenging to model, and buckling of the tape in compression, which alters the aerodynamic shape and disturbs the flow as shown in Figure 5.

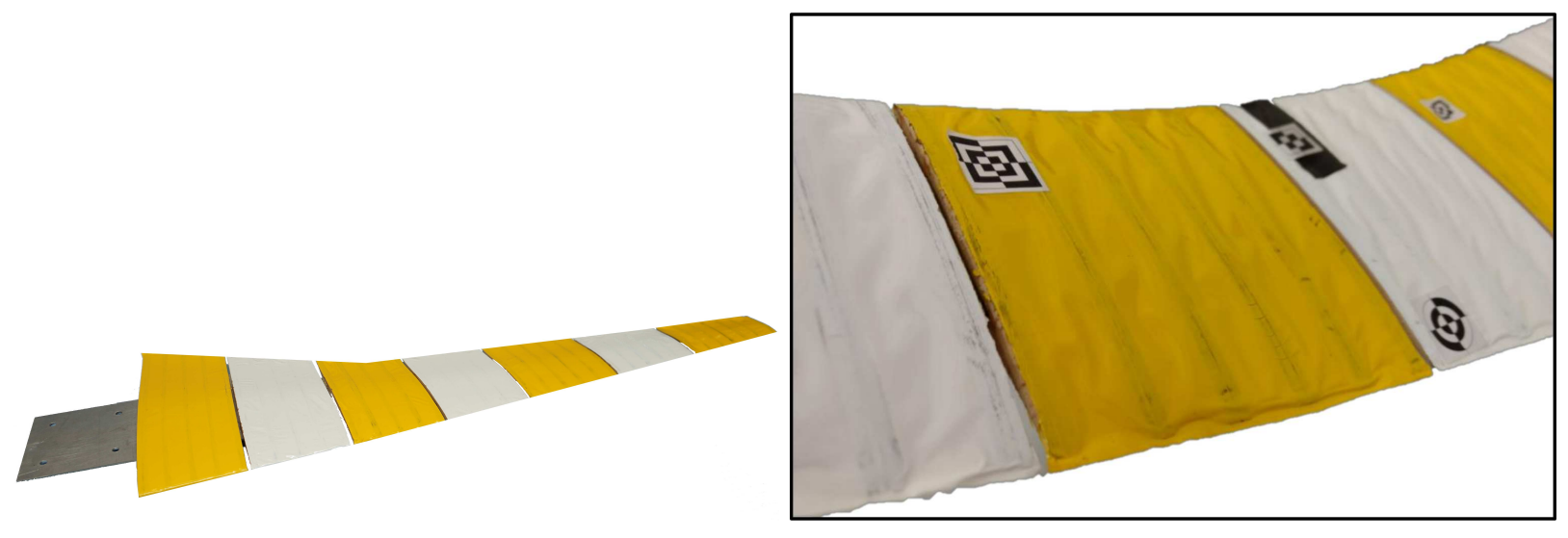

(a) Staticly scaled A-13 wing

(b) Scaled model tape buckling under bending

Figure 5. Previous Cranfield scaled A-13 programme wing buckling of aerodynamic surface

In order to overcome these problems, the XB-1 wing was printed with PolyJet technology. PolyJet is a 3D printing technology which allows the printing of multi-material parts, distributing structural properties along the part continuously. It works like an InkJet printer, dropping tiny particle of material and curing the layer with UV light. As shown in Figure 6a, XB-1 was printed with alternating rigid pods (grey) and elastic pods (red), forcing the wing to flex only along the flexible pods. It should be noted that because the PolyJet printer prints different materials in layers, there is no structural discontinuity between the pods. Furthermore, printing the elastic part allowed to overcome the buckling and additional stiffness issue.

The instrumentation and spar fixture locations can be accessed via a removable bottom cover, shown in Figure $6 \mathrm{~b}$. Figure $6 \mathrm{c}$ depicts the aluminium spar geometry, which as per design matches the required stiffness of the wing (allowing the skin stiffness to be considered negligible). The pillar interface, which transfers the aerodynamic load from the skin to the spar, is shown in Figure 6d with the cross section of the interaction in Figure 6e. 


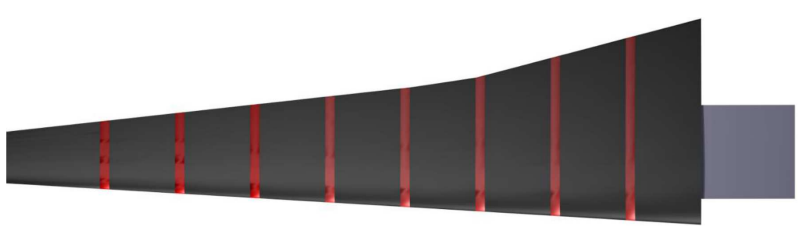

(a)

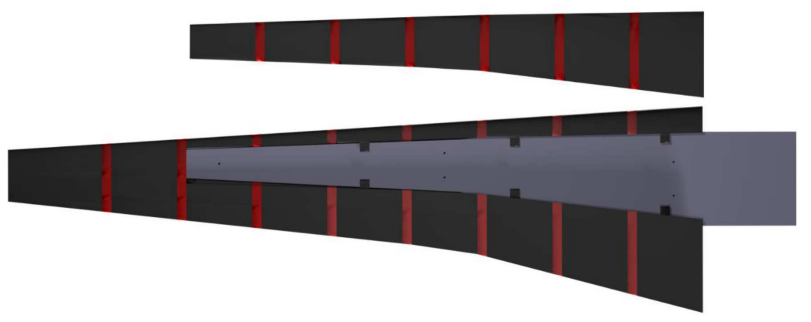

(b)

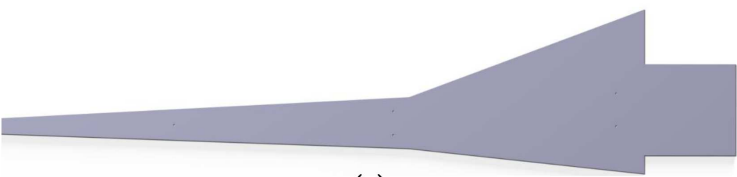

(c)

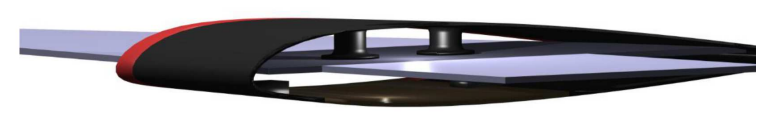

(d)

(e)

Figure 6. XB1 geometry

\section{B. Fluid-Structure Interaction Modelling}

The XB-1 test matrix focuses on measuring the static response of the wing under a defined angle of attack and steady flow conditions. As such, BEARDS ${ }^{T M}$ was used to define the stiffness matrix of the test wing, and the loading condition using MST. This aerodynamic loading was validated using the Athena Vortex Lattice (AVL) code (Figure 7) that is based in work of Mark Drela, Lamar, ${ }^{25}$ E. Lan and L. Miranda, ${ }^{26}$ and used to determine the theoretical static deflection of the wing, as shown in Figure 8, which gives a maximum tip deflection of $210 \mathrm{~mm}$ or $28 \%$ of the semi-span.

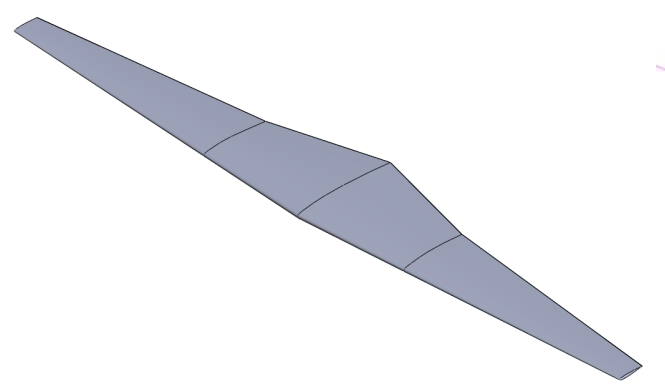

(a) CAD geoemtry of XB-1

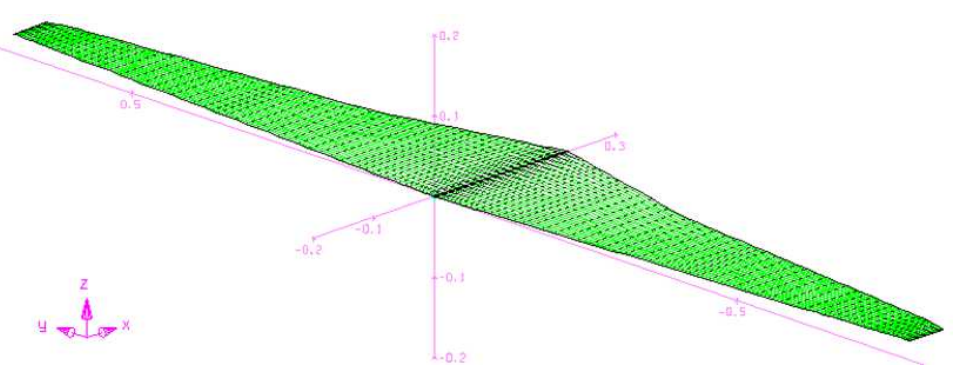

(b) AVL mesh set-up for XB-1

Figure 7. Athena Vortex Lattice (AVL) code set up for XB-1 analysis

Testing of the XB-1 wing is not to measure the dynamic response of the wing directly, this aspect is a further extension for XB-2. However, prediction of the dynamic response is important for wind tunnel safety, in making sure flutter modes are not excited at test speeds. Also validation of the BEARDS ${ }^{T M}$ solver for the dynamic response is required, as such a separate modal response test has been conducted using a frequency sweep on a shaker. The predicted structural modes of the XB-1 wing from the BEARDS ${ }^{T M}$ solver are given in Figure 9.

The Frequency Response Function (FRF) results from a 0-300 Hz sweep shaker testing are presented in Figure 10. The modal frequencies identified during the ground vibration test validate partially those predicted by BEARDS ${ }^{T M}$. The match is accurate for the first three modes, while it differs for the last two. The first five modes identified from the shaker test are $5.12 \mathrm{~Hz}, 22.02 \mathrm{~Hz}, 55.3 \mathrm{~Hz}, 110.1 \mathrm{~Hz}$, and $174.1 \mathrm{~Hz}$.

The FRF response from the shaker testing is obtained using input feedback data from PCB356B18 accelerometer placed on the shaker and the velocity at specific section from the laser vibrometer (Polytec OFV-505 Sensor Head), both of them sampling at $1600 \mathrm{~Hz}$. As these results are obtained using a laser vibrometer targeting a specific section, some modes are not captured from the experiment. During the test, 


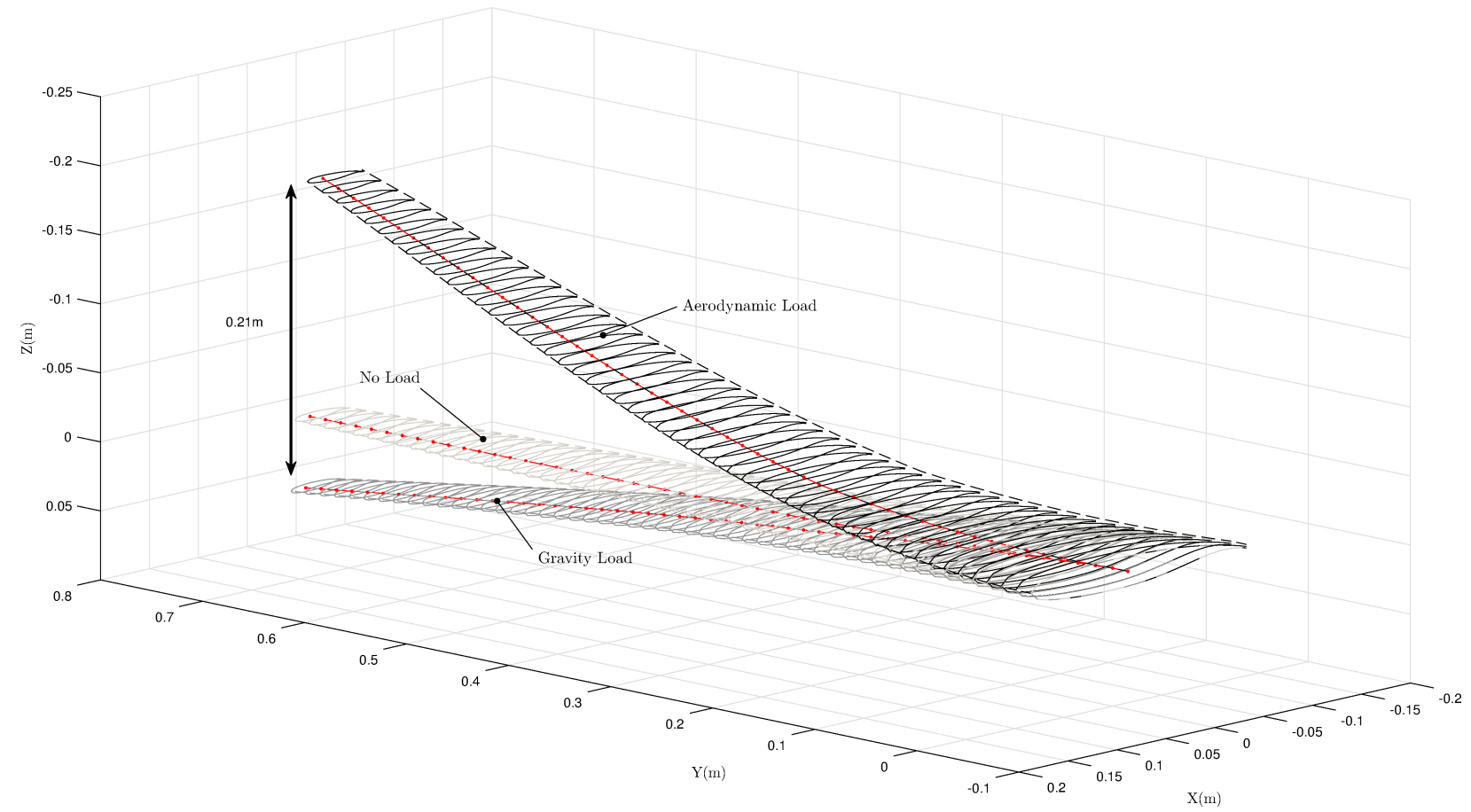

Figure 8. BEARDS XB-1 static deflection prediction using BEARDS ${ }^{T M}$ solver

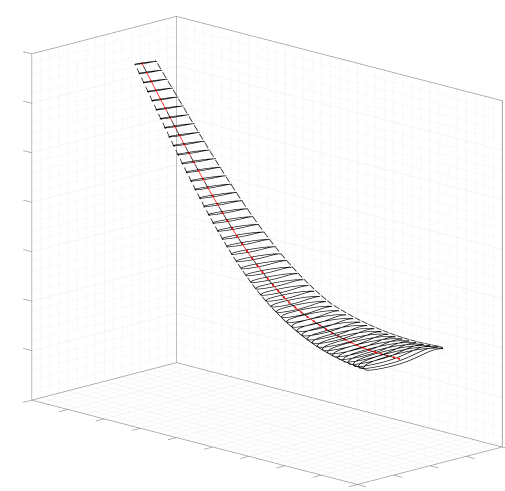

(a) Mode $1(6.0 \mathrm{~Hz})$

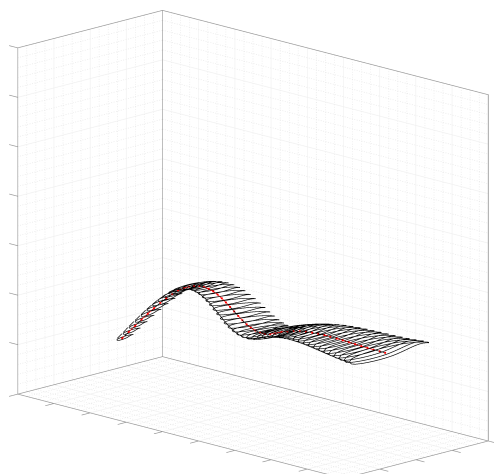

(d) Mode $4(72.7 \mathrm{~Hz})$

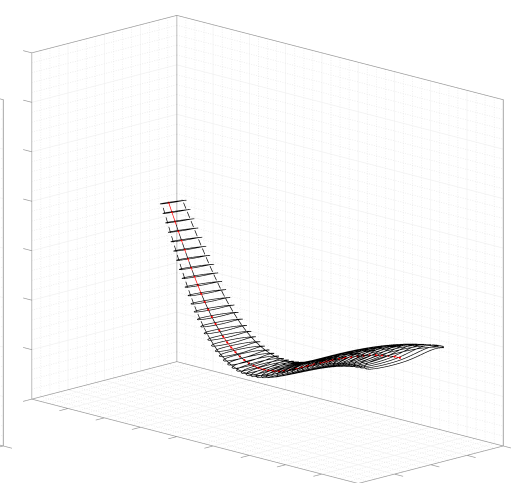

(b) Mode $2(22.7 \mathrm{~Hz})$

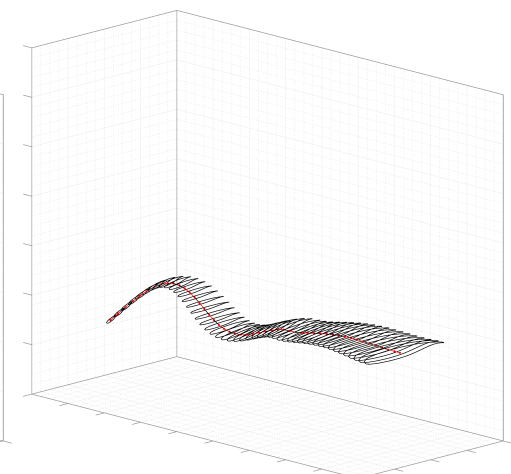

(e) Mode $5(151.6 \mathrm{~Hz})$

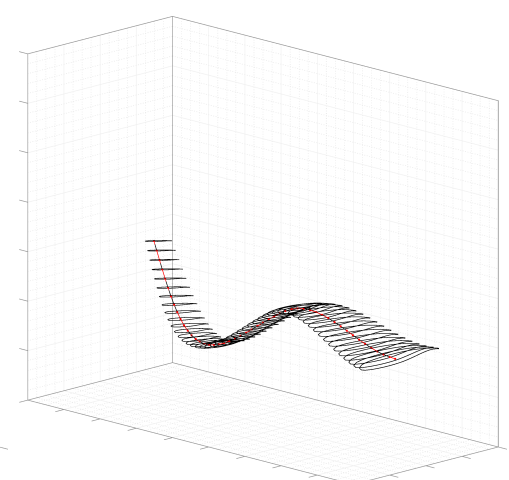

(c) Mode $3(58.0 \mathrm{~Hz})$

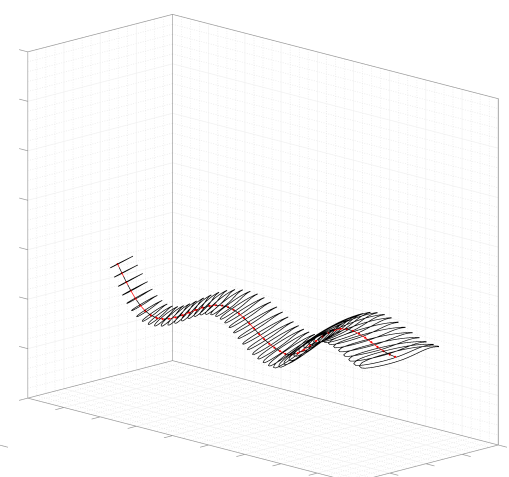

(f) Mode $6(189.7 \mathrm{~Hz})$

Figure 9. BEARDS XB-1 dynamic response prediction using BEARDSTM solver 
6-DOF IMUs placed on the spar were used to record modal frequencies transferring data to RaspberryPi board, as described later this section. It is important to stress that using the RaspberryPi setup alone, only the first two modes can be identified. This is due to the limited bit rate of the RaspberryPi I2C bus which allows for the test to transfer data at no more that $100 \mathrm{~Hz}$. Thus, to avoid aliasing issues, the maximum frequency of interest that can be sampled must be lesser than $50 \mathrm{~Hz}$, which is still in the bandwidth of interest for aeroelastic studies.

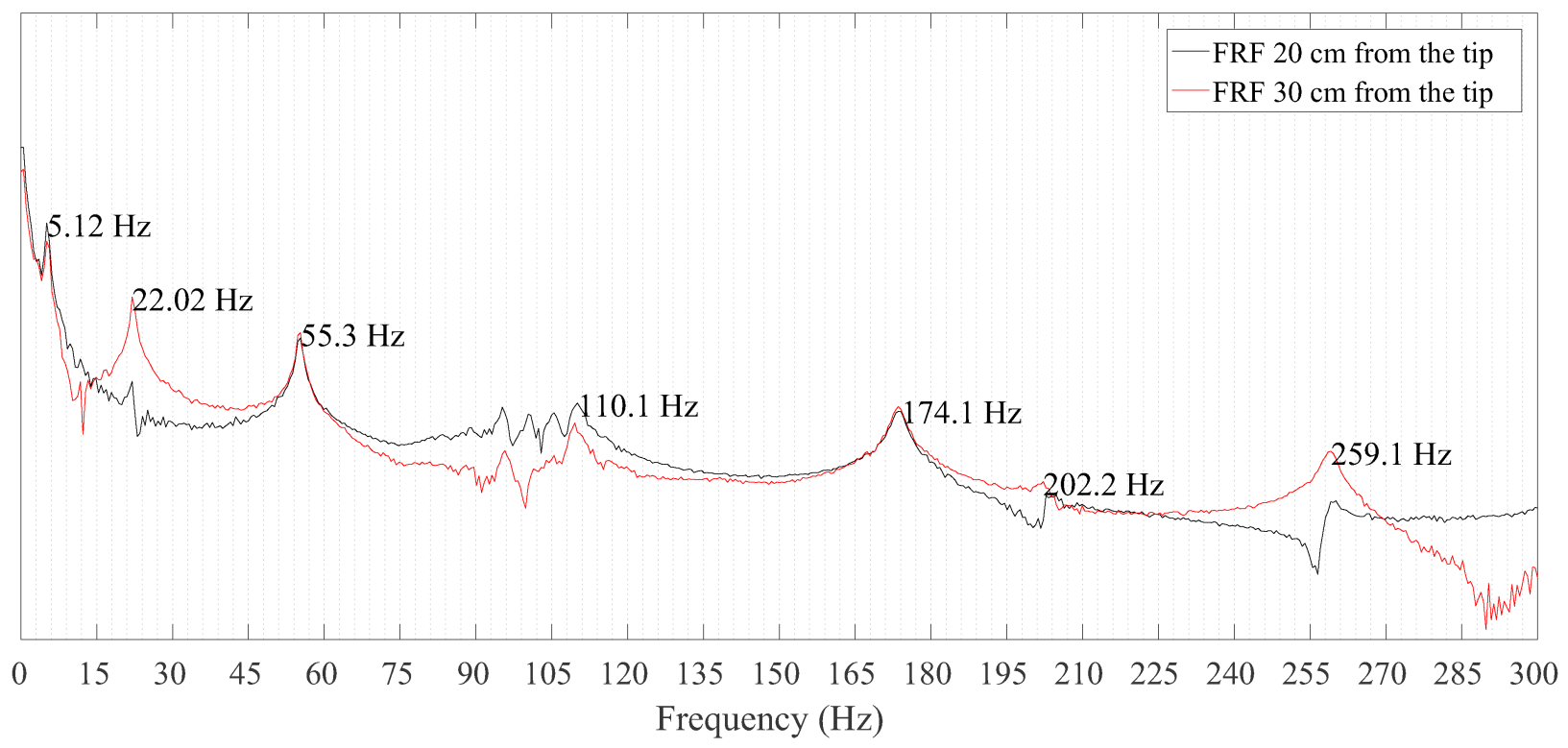

Figure 10. BEARDS XB-1 modal response from vibration test. The test has been run twice moving vibrometer in two different sections in order to identify clearly the natural frequencies. The vibrometer has been placed firstly at 20 from the tip and then at $30 \mathrm{~cm}$ from the tip.

\section{Instrumentation methodology}

In order to assess wing dynamics, the model was equipped with an aquisition system (Figure 11) of four Inertial Measurement Units (IMUs) distributed along the wingspan. The IMUs are 6-DOF sensors: 3-DOF accelerometers and 3-DOF gyroscopes. The placement of the sensors is shown in Figure 12. IMU 2 and IMU 3 are placed in the same section in order to compare rotational dynamics extrapolated from the data coupling of two different accelerometer readings against data obtained from a single gyroscope. The hardware used in this experiment was IMU breakout boards featuring Invensense MPU-6050 sensor, providing I2C interface. The chip is configurable, allowing different scale and precision both for the gyroscope and the accelerometer.

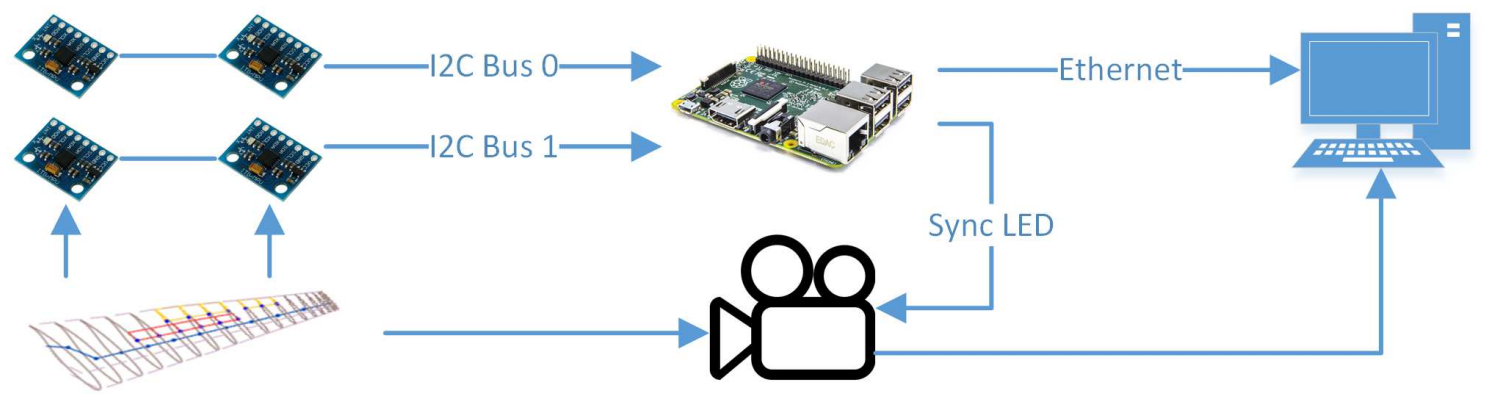

Figure 11. Instrumentation Architecture

In addition, Olympus i-Speed 2 high speed camera was used to track the displacement of the wingtip using two markers. The acquisition rate of the camera was set to $100 \mathrm{fps}$. A blinking LED has been used to synchronize data acquired by the IMUs and the video recorded by the camera. Images acquired by the 


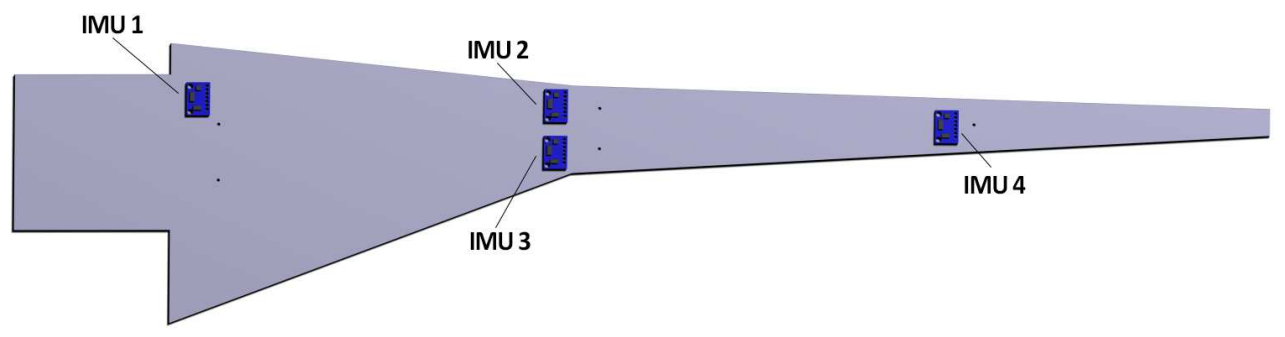

Figure 12. IMUs position

camera can then be used in a sensor fusion algorithm to estimate the displacement of different sections. Figure 13 shows part of the process for target tracking:

1. a frame of the recording is chosen in order to identify the targets to be tracked

2. the script identifies main target features to match in the recording (represented by green circles in the picture)

3. the script compares each frame features to the target ones and estimates the position of target once the feature is matched

4. the position of the target throughout all frames is then plotted and displacement calculated.

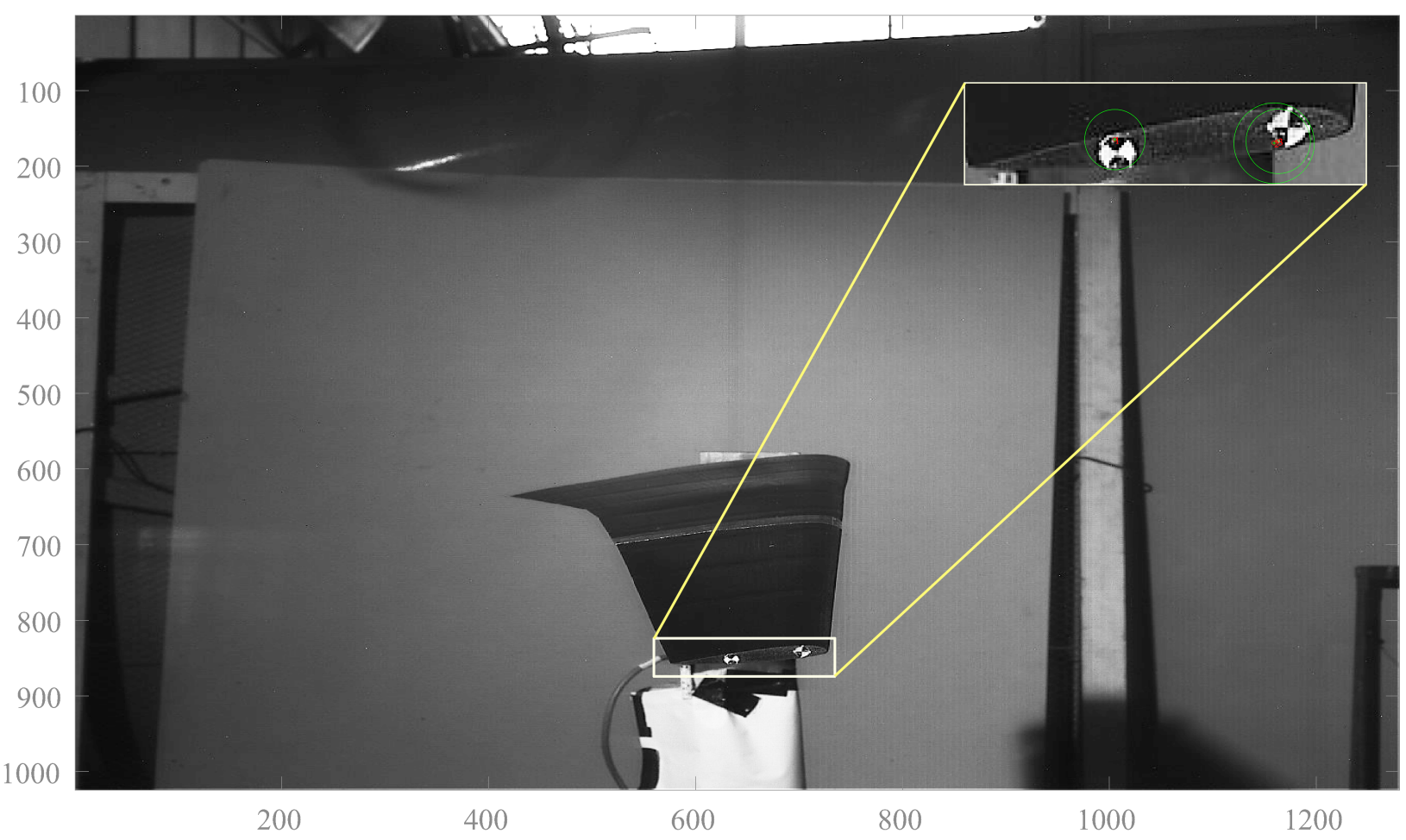

Figure 13. High speed camera frame used in the tracking script to identify the target. Highlighted in the yellow box, the marker shows the features recognized, circled in green.

Data from sensors was collected by a Raspberry Pi 2 Model B, which is also responsible for the LED synchronization. Due to the nature of the chips, the I2C addresses available for the MPU-6050 chip are only two, limiting the amount of sensors which can be placed on a single bus. It is possible to set a second I2C line on the Raspberry Pi 2 in addition to the standard one, allowing the device to read from 4 IMUs simultaneously. The sensors were read at $100 \mathrm{~Hz}$ due to a limitation of the I2C bus bit rate. 


\section{Weybridge Wind Tunnel Testing \& Discussion}

Flexibility of the wing is shown in Figure 14. The frames are taken from the high speed camera recording during wind tunnel tests run at $27 \mathrm{~m} / \mathrm{s}$ in the Weybridge wind tunnel facility in Cranfield University. As expected, the model is highly flexible and it undergoes high deformation without buckling or plastic

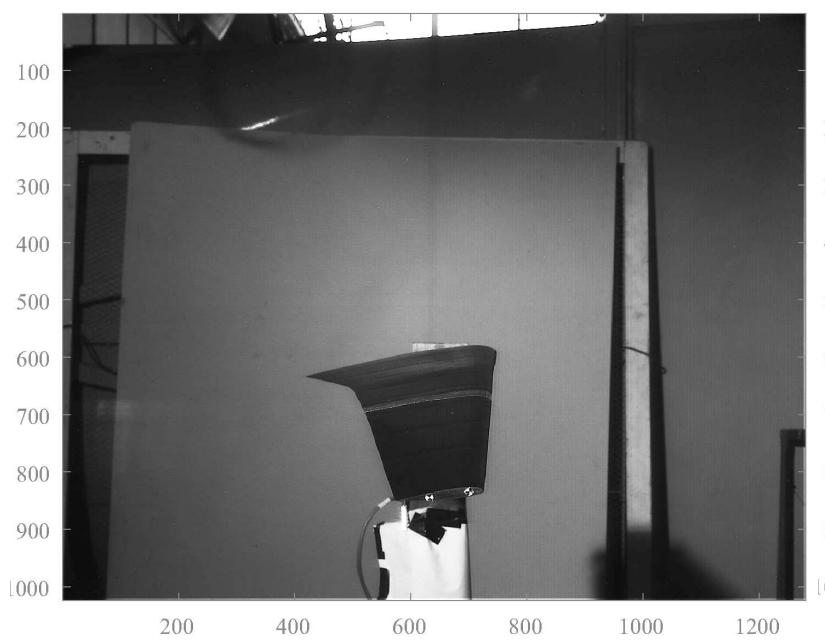

(a) Frame captured after $3 \mathrm{~s}$

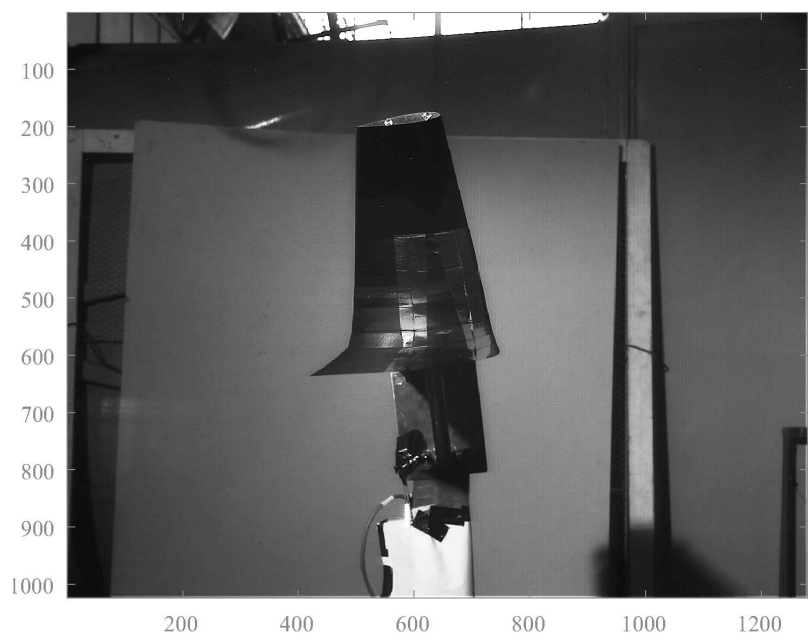

(c) Frame captured after $25 \mathrm{~s}$

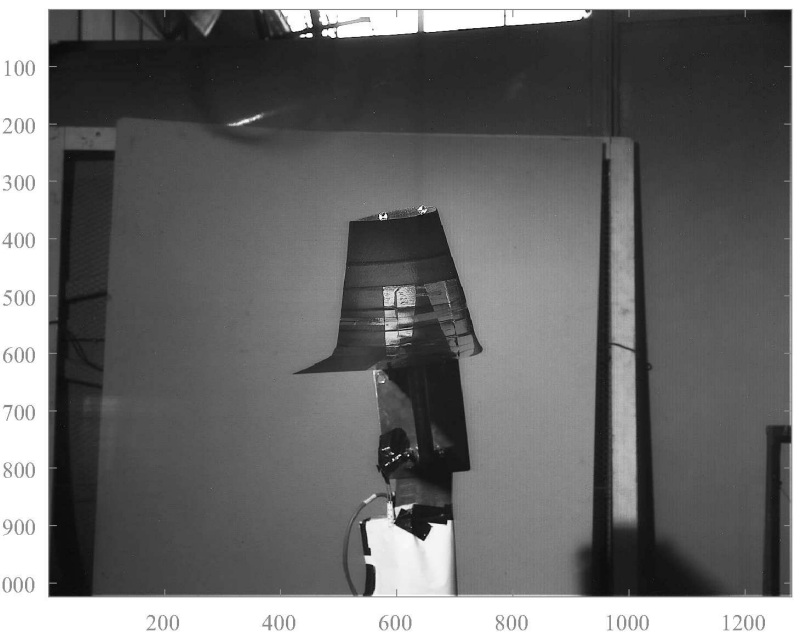

(b) Frame captured after $10 \mathrm{~s}$

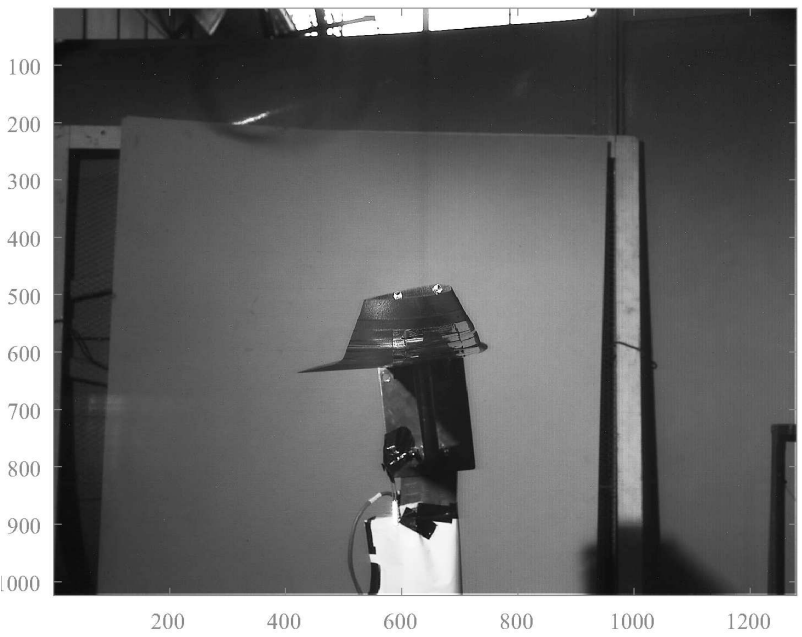

(d) Frame captured after $35 \mathrm{~s}$

Figure 14. Frame of XB-1 test recording acquired with the high speed camera which shows the flexibility of the model under aerodynamic load during wind tunnel tests.

\section{deformation.}

High speed camera recording shows that the skin is capable of effectively transferring the aerodynamic load to the spar whilst retaining the desired aerodynamic shape. Figure 15 shows the wingtip displacement of the XB-1 model during the same test mentioned above, $27 \mathrm{~m} / \mathrm{s}$ in the Weybridge wind tunnel. The test lasted 45 seconds. The first 19 seconds show the wing deforming due to the build up of aerodynamic load and move from its original shape under gravity load (black dots). It can also be observed from the horizontal displacement (red dots) that due to torsion effects the wing tends to bend backwards while the speed increases. After this time, approximately 11 seconds are spent in steady conditions where the wingtip is just vibrating around the steady value. Then the wind tunnel speed quickly reaches zero, unloading the wing, allowing it to come back the original position. Each dot shown in the figure represents an identified target in the frames acquired from high speed camera.

The test clearly shows the high flexibility of the model, which is able to deflect $238 \mathrm{~mm}$ at the maximum flow speed, about $32 \%$ of the model semispan. The total displacement is considered from the point when the 


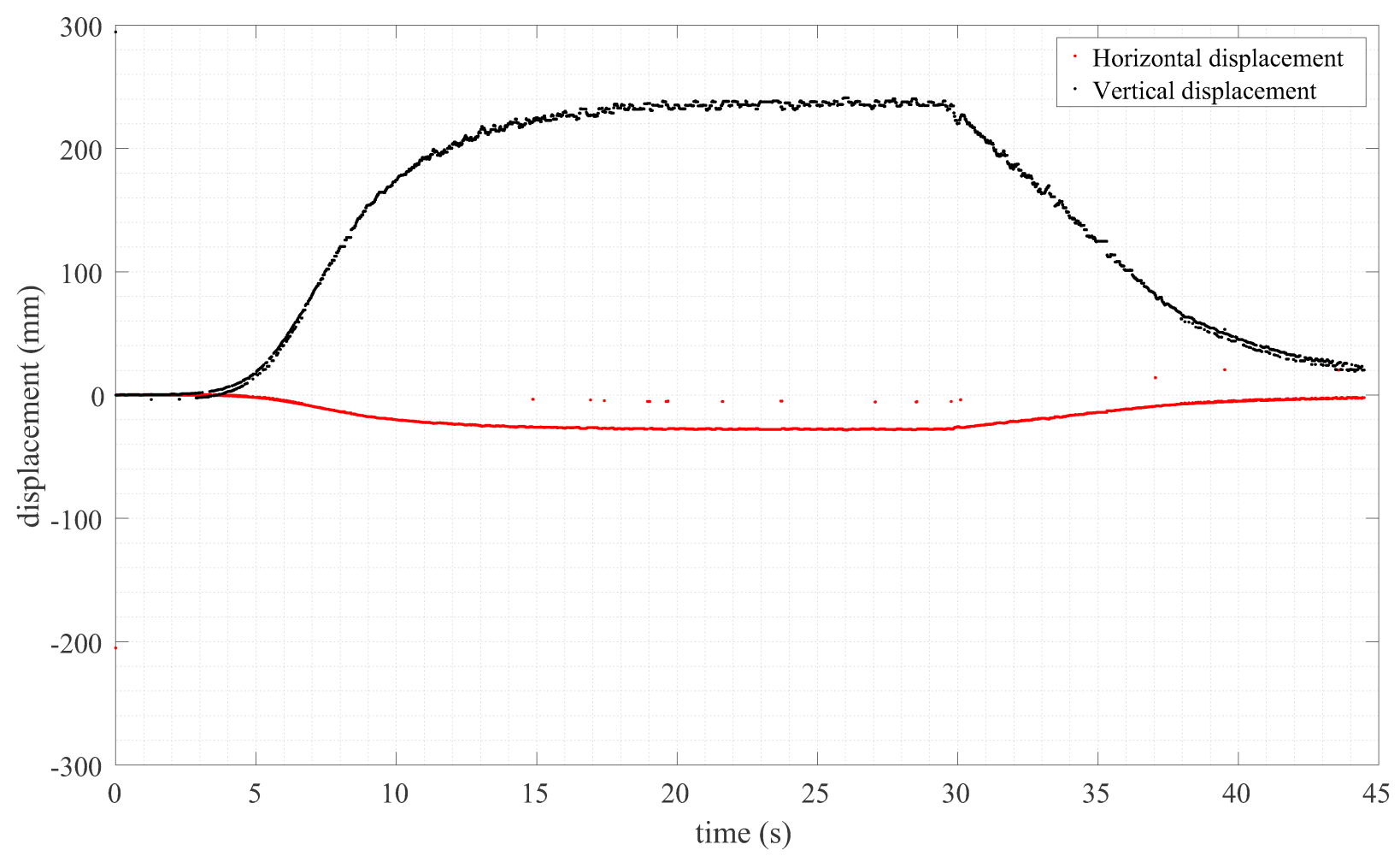

Figure 15. BEARDS XB1 Weybridge wind tunnel test results: results at $27 \mathrm{~m} / \mathrm{s}$ are shown. The black line shows the vertical displacement of the wingtip, while the red line shows the horizontal one.

wing is aerodynamically unloaded, under the gravity load only, to the time where the dynamic pressure is at the maximum. The maximum horizontal displacement is $24 \mathrm{~mm}$, which demonstrates that torsion plays an important role in the aerodynamic behaviour of flexible wings, able to change significantly the local angle of attack. Dynamics of the bending of each IMU is shown in Figure 16 where the angular velocity around

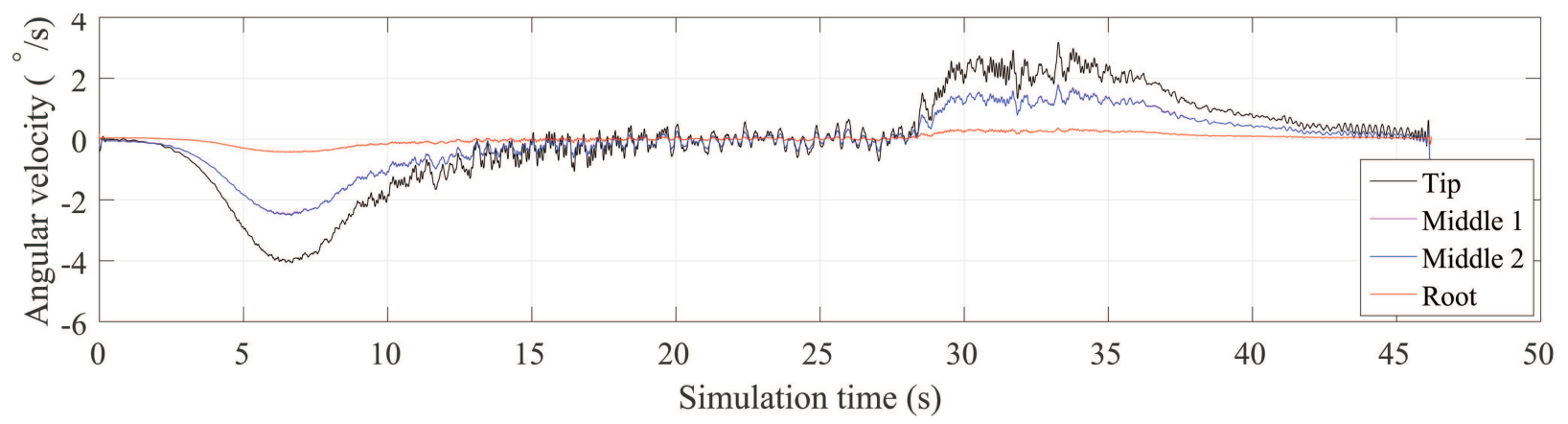

Figure 16. Angular velocity around the local chord axis. Negative values show an upward bending of the section.

the chord-wise axis in the sensor local frame is plotted. The figure shows preliminary results of the IMU data post-processing. The angular velocity displayed would represent the absolute angular rate if no twist or lag happened. For this discussion, it is assumed that each section undergoes on pure bending and the data plotted are representative for the absolute angular velocity. Considering as positive downwards bending, the wing rotates initially upwards, reaching a maximum rotation velocity of $4^{\circ} / \mathrm{s}$ at the tip section. The final section of the plot shows a positive downwards rotation when the wing goes back to initial position. The figure shows also that data from the two IMUs at middle sections match, as it was expected being the bending axis parallel to the chord. All gyros data shown are post-processed using a low-pass filter to remove noise. 


\section{E. Conclusions and Lessons Learnt}

As stated previously, primary aims of Phase I are: to develop manufacturing techniques for flexible wind tunnel models and to recognize possible issues, such as deformation prediction and scaling methodology, in order to apply the knowledge to Phase II. The most significant findings from Phase I of this programme were as follows:

1. Polyjet printing technology is well suited to print flexible skin able to keep the wing aerodynamic shape, avoiding buckling and stiffness addition. Stronger leading edge (LE) and trailing edge (TE) sections are required as it was seen that cracks are likely to happen due to the high stress induced by local curvature. The XB-2 model will be designed with solid LE and TE sections.

2. The idea of having flexible-rigid pods makes the skin flexible allowing the use of simple pillars to transfer aerodynamic load to the spar. The use of a detached bottom skin section will be replaced with windows to access the inner part of the model. Having a closed section proved to be critically important when keeping the aerodynamic shape.

3. $\mathrm{BEARDS} \mathrm{S}^{T M}$ is partially able to predict deformation of the scaled wing. An error of $12 \%$ in the predicted and measured displacement was found. This is due to experimental uncertainties and modelling approximation that will be accounted for the Phase II of the programme.

4. The adopted approach for data acquisition was well suited to monitoring and logging the dynamics of interests. The possibility to use two different acquisition boards in order to increase the sampling frequency is considered for Phase II.

BEARDS Phase II is currently under development and the model is already mostly designed recognizing knowledge gained in Phase I. An overview of the XB-2 design is then given in the next section.

\section{Phase II - eXperimental BEARD 2 (XB-2)}

With a wing semi-span of $26 \mathrm{~m}$, tip chord $1.2 \mathrm{~m}$, root chord $3.3 \mathrm{~m}$, the XB2 aircraft has an aspect ratio of around 23 (see Figure 17). The planform is designed to be simple, with no sweep, dihedral or twist, as well as containing no wing cranks. This academic wing design means there are less variables for the first wind tunnel model to be designed through the BEARDS process.

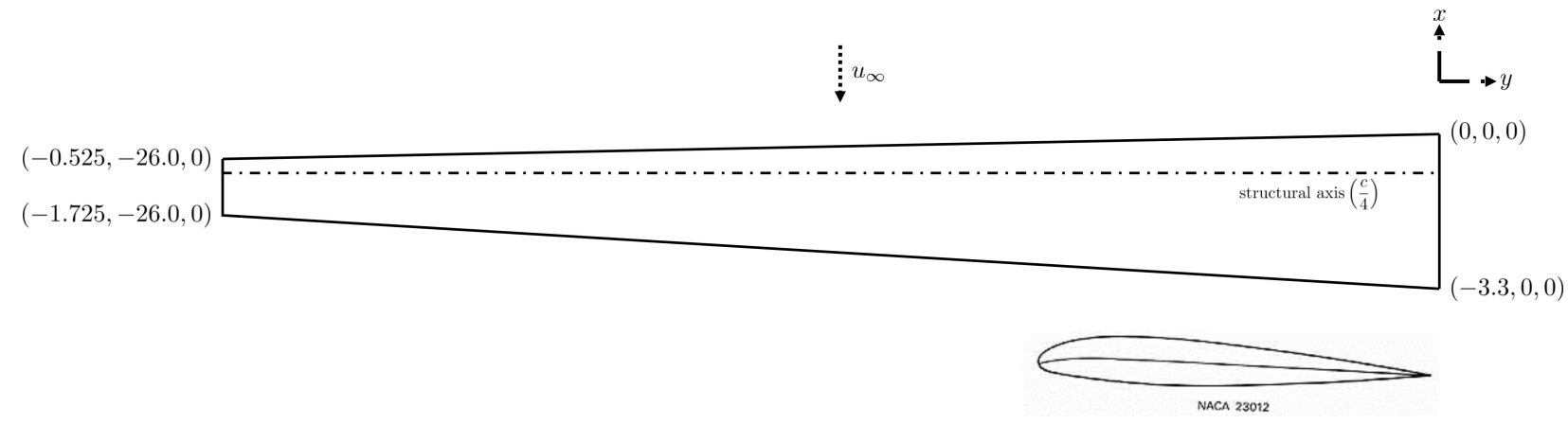

Figure 17. XB-2 Planform Definition

Due to the size of the wind tunnel test section, a geometric scaling factor of 1:16 is selected for the subscale model, giving a semi-span of $1.625 \mathrm{~m}$. In order for the Froude number to be scaled, the wind-tunnel speed needs to be 4 times slower than the real aircraft. As a results, the dynamic response of the sub-scale model in the frequency domain is expected to be 4 times higher.

Furthermore, the sub-scale model is built to represent a cruise flight altitude of $35,000 \mathrm{ft}$ at $190 \mathrm{~m} / \mathrm{s}$. This number is chosen not only due to the velocity scaling, but also due to the mass and inertia scaling, as the sub-scale model, tested at sea level will be heavier, making it easier to manufacture and design.

The spar design process only considers the stiffness matrix $\mathrm{K}$ and involves two steps:

(i) the isolation of the inertia properties from the scaled stiffness matrix $\mathrm{K}$ 
(ii) to run a minimization algorithm which matches the inertia of the spar sections and the ones derived from the $\mathrm{K}$ matrix

During the first phase, for each node, which physically corresponds to the spar section, inertia properties such as bending inertia $E I_{x x}$, in-plane inertia $E I_{z z}$ and torsional inertia $G J_{y}$ are derived from the scaled K. In the minimization algorithm, a gradient-based optimizer is used to minimize the cost function $\mathrm{J}$ described as:

$$
J=\left(E I_{x x}-\widetilde{E I}_{x x}\right)^{2}+\left(E I_{z z}-\widetilde{E I}_{z z}\right)^{2}
$$

Where $\mathrm{E}$ of the model is the Young modulus of the material chosen to manufacture the spar (in the XB-2 case Aluminium $E=70 G P a)$. The inertia I depends on the definition of the chosen cross section. It has been found that for XB-2 a cross-shape section is the best option to ensure bending and in-plane inertia are closely matched. The output from the spar topology minimisation process is given in Figure 18, where the black line represents the flange and the red line represents the web of the cross section.

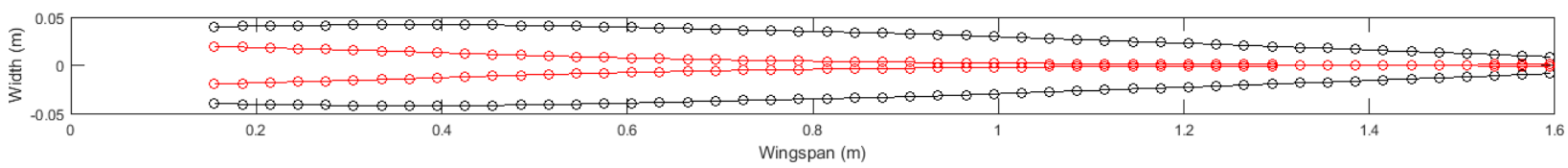

Figure 18. XB-2 Spar Topography Minimisation Output

An overview of the XB-2 aerodynamic skin design is given in Figure 19, showing how the lessons learnt from the XB-1 design have tailored the XB-2 design to be a more robust model. Key changes from XB- 1 to $\mathrm{XB}-2$ include:

1. Windows in place of a large section removed to access spar and instrumentation. This allows the flexible sections to be continuous closed sections.

2. Increase in material thickness in rigid sections to keep aerodynamic shape.

3. Inclusion of control surfaces, two spoilers and aileron.

4. Increased capability of modularity which allows inclusion of a folding wingtip at a later design stage.

5. Optic fibre strain measurement for instrumentation.

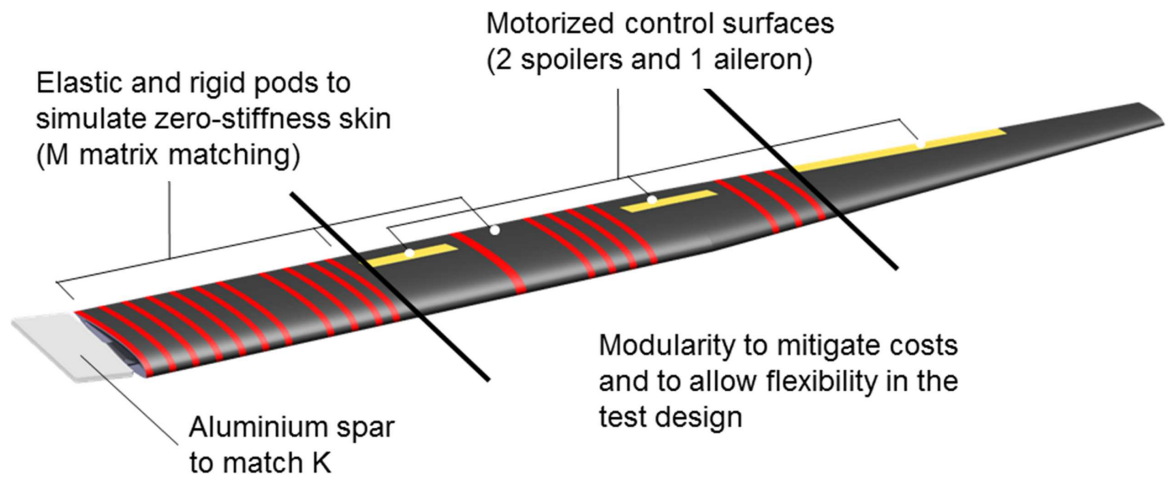

(a)

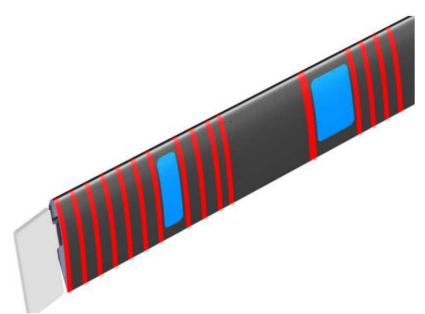

(b)

Figure 19. XB-2 Preliminary Design for Manufacture 


\section{Acknowledgments}

The authors have completed this work as a part of their respective doctorate studies, and as such would like to express their thanks to each individual funding body, Innovate UK, the UK Engineering and Physical Sciences Research Council (EPSRC), Lembaga Pengelola Dana Pendidikan (LPDP) of Indonesia and Consejo Nacional de Ciencia y Tecnologa (CONACYT) of Mexico, without which the present study could not have been completed. In addition the authors wish to thank Airbus Group and the Agile Wing Integration programme for their insight into this work. Thanks to Luca Zanotti Fragonara and Ivan Petrunin of Structural Dynamics Laboratory, Centre for Autonomous and Cyberphysical Systems, Cranfield University for their help in the vibration test.

\section{References}

${ }^{1}$ Birkhoff, G., Hydrodynamics, Princeton University Press, 1960.

${ }^{2}$ Duncan, W., Physical similarity and dimensional analysis, Edward Arnold and co., 1953.

${ }^{3}$ Ricciardi, A., Canfield, R., Patil, M., and Lidsley, N., "Nonlinear Aeroelastic Scaled-Model Design," Jounal of Aircraft, Vol. 53, 2016, pp. 20-32.

${ }^{4}$ Jordan, T. L., Langford, W. M., and Hill, J. S., "Airborne Subscale Transport Aircraft Research Testbed - Aircraft Model Development," Proceedings of the AIAA Guidance, Navigation, and Control Conference and Exhibit, 2005, 2005.

${ }^{5}$ Chambers, J., Modeling Flight, NASA, 2010.

${ }^{6}$ Bradley, M. K. and Droney, C. K., "Subsonic Ultra Green Aircraft Research Phase II: N+4 Advanced Concept Development," Tech. rep., NASA, 2012.

${ }^{7}$ Ryan, J., Bosworth, J., and Burken, J., "Current and Future Research in Active Control of Lightweight, Flexible Structures Using the X-56 Aircraft," AIAA SciTech Forum, 13-17 January 2014, National Harbor, Maryland, 2014.

${ }^{8}$ Jones, J. and Cesnik, C., "Nonlinear Aeroelastic Analysis of the X-56A Multi-Utility Aeroelastic Demonstrator," AIAA SciTech Forum, 4-8 January 2016, San Diego, California, USA, 2016.

${ }^{9}$ Bisplinghoff, R., Ashley, H., and Halfman, R., Aeroelasticity, Dover, 1996.

${ }^{10}$ Nguyen, N. T., Ting, E., Chaparro, D., Drew, M. C., and Swei, S. S.-M., "Multi-Objective Flight Control for Drag Minimization and Load Alleviation of High-Aspect Ratio Flexible Wing Aircraft," 58th AIAA/ASCE/AHS/ASC Structures, Structural Dynamics, and Materials Conference, American Institute of Aeronautics and Astronautics, Reston, Virginia, jan 2017.

${ }^{11}$ Simpson, R., Palacios, R., Hesse, H., and Goulart, P., "Predictive Control for Alleviation of Gust Loads on Very Flexible Aircraft," 55th AIAA/ASMe/ASCE/AHS/SC Structures, Structural Dynamics, and Materials Conference, No. January, 2014, pp. $1-25$.

${ }^{12}$ Castrichini, A., Hodigere Siddaramaiah, V., Calderon, D. E., Cooper, J. E., Wilson, T., and Lemmens, Y., "Nonlinear folding wing tips for gust loads alleviation," Journal of Aircraft, Vol. 53, No. 5, sep 2016, pp. 1391-1399.

${ }^{13}$ ESDU 89014, "Normal force, pitching moment and side force of forebody-cylinder combinations for angles of attack up to 90 degrees and Mach numbers up to 5," 1990.

${ }^{14} 88031$, E., "Lift and longitudinal forces on propeller/nacelle/wing/flap systems," 2009.

${ }^{15}$ Cavagna, L., Ricci, S., and Riccobene, L., "Structural Sizing, Aeroelastic Analysis, and Optimization in Aircraft Conceptual Design," Journal of Aircraft, Vol. 48, No. 6, nov 2011, pp. 1840-1855.

${ }^{16}$ Andrews, S., Modelling and simulation of flexible aircraft: handling qualities with active load control, Ph.D. thesis, Cranfield University, School of Engineering, 2011.

${ }^{17}$ Ricciardi, A. P., Eger, C. A. G., Canfield, R. A., and Patil, M. J., "Nonlinear Aeroelastic-Scaled-Model Optimization Using Equivalent Static Loads," Journal of Aircraft, Vol. 51, No. 6, 2014, pp. 1842-1851.

${ }^{18}$ Timoshenko, S. and Goodier, J. N., Theory of elasticity, McGraw-Hill, 3rd ed., 1970.

${ }^{19}$ Przemieniecki, J. S., Theory of Matrix Structural Analysis, Dover, 1985.

${ }^{20}$ Theodorsen, T., "General theory of aerodynamic instability and the mechanism of flutter," Tech. rep., NACA-TR-496, National Advisory Committee for Aeronautics, 1935.

${ }^{21}$ Theodorsen, T. and Garrick, I., "Non stationnary flow about a wing-aileron-tab combination including aerodynamic balance," Tech. rep., NACA-TR-736, National Advisory Committee for Aeronautics, 1942.

${ }^{22}$ Weissinger, J., "The lift distribution of swept-back wings," Tech. rep., NACA-TN- 1120, National Advisory Committee for Aeronautics, 1947.

${ }^{23}$ DeYoung, J. and Harper, C., "Theoretical symmetric span loading at subsonic speeds for wings having arbitrary plan form," Tech. rep., NACA-TR-921, National Advisory Committee for Aeronautics, 1948.

${ }^{24}$ Kissinger, T., Chehura, E., Staines, S. E., James, S. W., and Tatam, R. P., "Dynamic fiber-optic shape sensing using fiber segment interferometry," Journal of Lightwave Technology, 2017, pp. 1-1.

${ }^{25}$ Lamar, E., "Vortex-Lattice Fortran program for estimating subsonic aerodynamic characteristics of complex planform," Tech. Rep. TND-6142, 1971.

${ }^{26}$ Miranda, L. R. and Elliott, R. D., "A Generalized Vortex Lattice Method for subsonic flow applications," Tech. Rep. NASA-12972, 1977. 
2018-01-13

Flexible high aspect ratio wing: Low cost experimental model and computational framework

Pontillo, Alessandro

AIAA

Pontillo A, Hayes D, Dussart GX, et al., (2018) Flexible high aspect ratio wing: low cost experimental model and computational framework. In: Proceedings of 2018 AIAA Atmospheric Flight Mechanics Conference, 8-12 January 2018, Kissimmee, Florida, USA, Paper number AIAA 2018-2014

http://dx.doi.org/10.2514/6.2018-1014

Downloaded from Cranfield Library Services E-Repository 